\title{
Implementation of Fuzzy Logic Type-2 on Mobile Robot Navigation System
}

\author{
Ade Silvia Handayani ${ }^{1}$ Sarjana $^{1}$ Jefri Alkausar ${ }^{1}$ Nyayu Latifah Husni ${ }^{1, *}$ \\ ${ }^{1}$ Electrical Department, Politeknik Negeri Sriwijaya \\ *Corresponding author.Email: nyayu_latifah@polsri.ac.id
}

\begin{abstract}
Recently, robot used by human to make a hard activity become easier. Robot give human more advantages and more conveniences. They can be easily programmed and they never feel tired or exhausted. Even so, implementing mobile robot's navigation system is not easy as it seems. In this research, it will discuss how the fuzzy logic type-2 on mobile robot's navigation system. Parameters inputs for the mobile robot will be the distance, and the outputs will be driver motor of mobile robot itself. The robot could avoiding the obstacles and explore a new area by itself.
\end{abstract}

Keywords: Mobile Robot, Navigation, Fuzzy Logic Type-2

\section{INTRODUCTION}

The technology that growing rapidly, recently make some progress, especially in robotics. This development have become a serious highlight for research world in the last period, mainly for smart robot and mobile robot. this is because the role of this robot can be used as a substitutes for human work, specifically human work in a dangerous cope, such as exploring an area that already contaminated by nuclear radiation, exploring an area that have never been touched by human before, and as a scouter for military operation [1].

Mobile robot can be interpreted as an electroniccomputer device, and arranged until it becomes a system to guess a surrounding area and translating it, with all the sensor in the mobile robot. Have a capability to analyse situation of the surrounding area and can do a movement on facing the situation in the environment [2]. Some of the mobile robot model have been developed and have certains control navigation system.

Control navigation system is a method to determine the movement to be taken by the robot in the existing environment. Smart navigation implemented in mobile robot, so the robot can determine a right decision for the robot movement by using fuzzy logic [3], [4].

Fuzzy logic system first introduced by Prof. Lotfi Zadeh to process information and data that have an uncertainty value to make a decision [5], [6]. This is a right method to design controller that can give a best performance in solving problems of uncertainty and inaccuracy [7], [8]. Fuzzy logic system make a maths formula from a basic knowledge, that has been proofed efficiently in so many implementations, and now it's been eye catching for a lot of researchers and has been succeeded applied into a real world [9].

Fuzzy logic type-1 is the most used type. But, fuzzy logic type- 1 can only resolve limited amount level of uncertainty, while when it applicated quite a number of sources with a high level uncertainty [10], [11]. But, it becomes a milestone for fuzzy logic type- 2 created.

Fuzzy logic type-2 is a Soft Computing (SC) technique to solve a problem of uncertainty, and inaccuracy to earn a stronger value number [10], [11]. But in implementing of this logic system, it's hard to be applicated in mobile robot. Because, it needs a quite long calculation time and a high computation cost.

The main purpose of this paper is to make a research about how to implemented a fuzzy logic type-2 into a mobile robot. So the calculation for the output, after it gets the input will be using fuzzy logic type- 2 as the algorithm.. 


\section{FUZZY LOGIC TYPE-2}

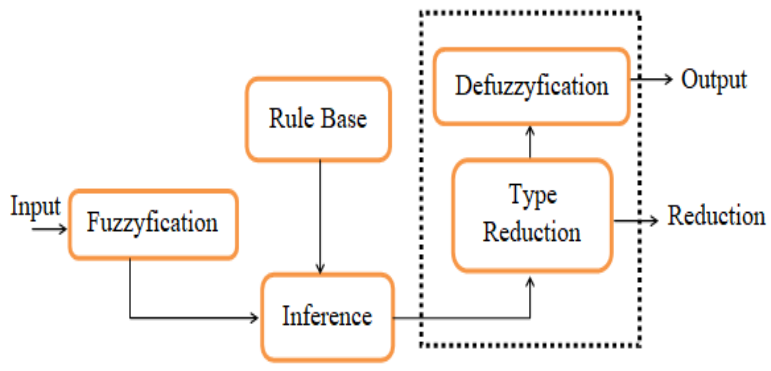

Figure 1. Fuzzy Logic Type-2 Diagram

Fuzzy logic type-2 consists of four main processes, which are fuzzification, decision-making (inference) / rule base, type reduction, and the last is defuzzification. The diagram that can be found in Figure 1 for fuzzy logic type-2 almost the same as fuzzy logic type-1, but the difference between these logical system is after getting a results which are taken out by the inference, continued by doing a reduction to change the sets contained in fuzzy logic type-2 into the fuzzy logic type-1 sets again, so the results of fuzzy logic type-1 that already defuzzified become a stronger value which are contained on the output of fuzzy logic type-2 [7].

Uncertainty value number in fuzzy logic type-2 not just getting a strong value as an end point of the membership function, but in fuzzy logic type-2 also gain another value which may use to represent a linguistic value.

\section{EXPERIMENTAL SETUP}

\subsection{Mobile Robot Hardware Design}

Designing the hardware for the mobile robot using Arduino Mega 2560 as the module that already made based on a sketch of the mobile robot to applied fuzzy logic type-2 as the navigation of the mobile robot itself. The following are the results that have been achieved in the making of mobile robot hardware.

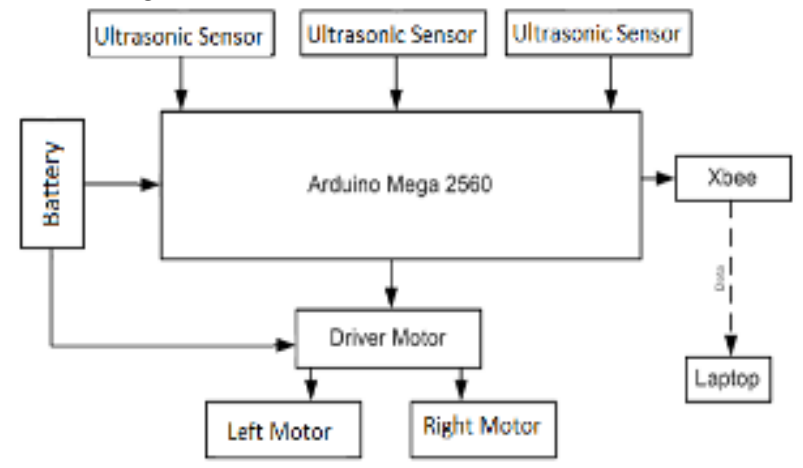

Figure 2. Mobile Robot Design

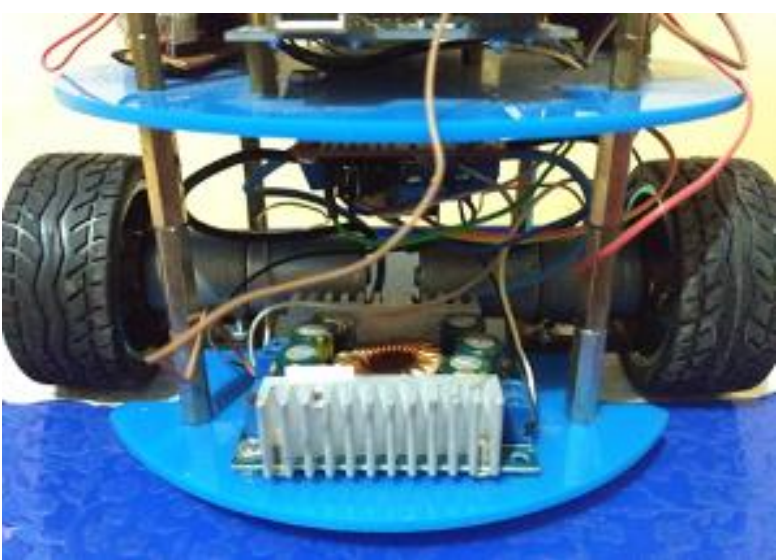

Figure 3. 1st Level, Driver Motor

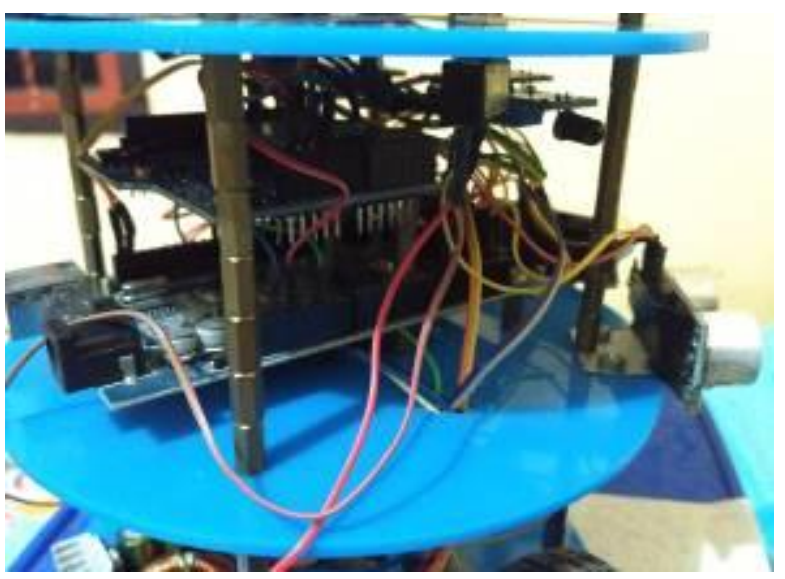

Figure 4. 2nd Level, Arduino, XBee, and Ultrasonic Sensor

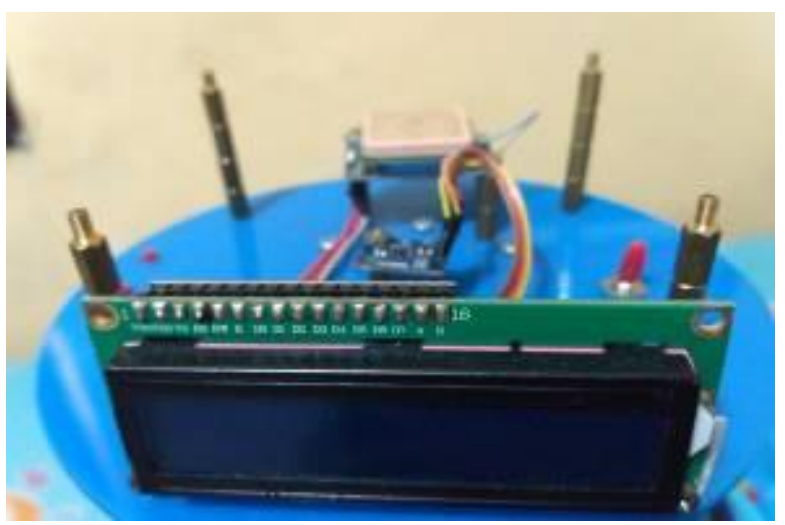

Figure 5. 3rd Level, LCD 16x2, Compass, and GPS

In the figure 3 until the figure 5 are the main components used in the making of this mobile robot, with some different purposes. Just like Arduino Mega, in mobile robot arduino mega have a task to giving order, processing all the input and arrange the output. XBee have a function as a communication tool between one robot and another. XBee have a function as a communication tool to send the data of the input and the output from the mobile robot that already gained by the sensor and already processed by the arduino mega to the computer or laptop with an extra application in the computer or laptop. LCD $16 x 2$ works as a display to 
choose an action to do by the mobile robot, that already programmed before. Compass HMCL5883L as an indoor direction tools, and GPS Neo 6M have a function as an outdoor direction tools.

There are 3 ultrasonic sensor used in this mobile robot placed on the left side of the mobile robot with an $45^{\circ}$ angle, front side of the mobile robot with an $90^{\circ}$ angle, and on the right side with an $135^{\circ}$ angle, as can be seen in figure 4 . Driver motor have a function as adjust the motor movement, the speed and motor DC direction sets in arduino. Form of the driver motor for mobile robot can be seen in figure 3

\subsection{Mobile Robot Software Design}

By the testing that have already done, the software obtained so the robot can move well and the data transmitted from the mobile robot can be received by the computer or laptop well. The following are a source coding that used in the arduino mega and the application used for the computer or the laptop).

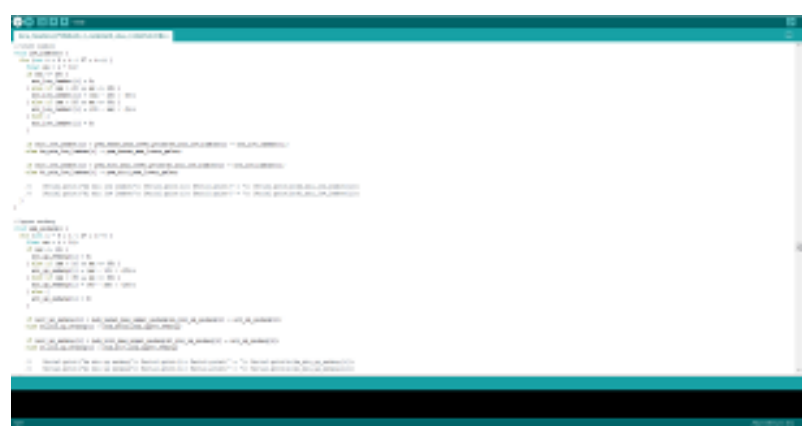

Figure 6. Fuzzy Logic Type-2 Calculation Coding

Figure 6 above shown a piece from the coding that used in arduino mega for the mobile robot. The section that already cut off in figure 6 is the part from calculation of fuzzy logic type- 2 for the reduction type, but it is already translated into a machine language so it can be used for arduino mega. As can be seen in figure 6 contained cutted pieces just like reduction type did

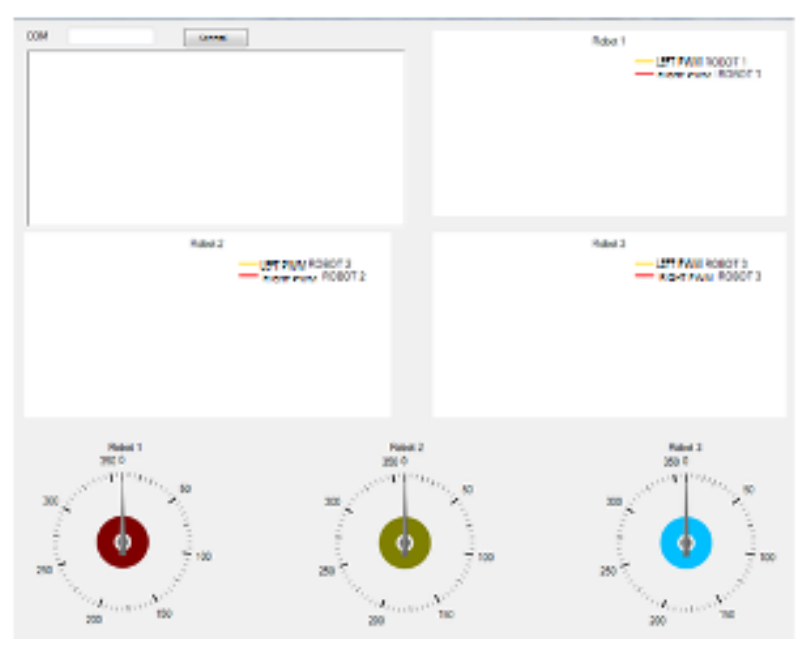

Figure 7. Application Interface On Laptop
Transmitting data sended by the XBee on the mobile robot will be using application that already made, and the interface of the application can be seen in figure 7. This application will be show the value results sended by robot 1, 2, and 3. Also the graphic of Left PWM and Right PWM movement will be shown on the application. The movement of the robot will be shown as a compass, just right at the bottom of the application interface

\subsection{Fuzzy Logic Type-2 As The Navigation System}

The value number that will be used by the fuzzy logic type- 2 for the input of the mobile robot will be shown in table 1 below :

Table 1. Input Parameter From Ultrasonic Sensor

\begin{tabular}{cccccc}
\hline Input & \multicolumn{5}{c}{ Parameter $(\mathrm{a}, \mathrm{b}, \mathrm{c}, \mathrm{d}, \Delta)$} \\
\hline Near & 0 & 0 & 20 & 40 & 5 \\
UpperNear & -5 & -5 & 25 & 45 & 5 \\
LowerNear & 5 & 5 & 15 & 35 & 5 \\
Far & 35 & 55 & 60 & 60 & 5 \\
Upper Far & 30 & 50 & 65 & 65 & 5 \\
LowerFar & 40 & 60 & 55 & 55 & 5 \\
\hline
\end{tabular}

The value number for the output of the Left PWM and the Right PWM for the mobile robot will be shown in table 2 :

Table 2. Output Parameter Left PWM and Right PWM

\begin{tabular}{ccccc}
\hline Output & \multicolumn{4}{c}{ Parameter (a, b, c, $\Delta)$} \\
\hline Fast & 45 & 140 & 240 & 10 \\
UpperFast & 35 & 140 & 250 & 10 \\
LowerFast & 55 & 140 & 230 & 10 \\
Medium & 20 & 35 & 50 & 10 \\
UpperMedium & 10 & 35 & 60 & 10 \\
LowerMedium & 30 & 35 & 40 & 10 \\
Slow & 10 & 25 & 40 & 10 \\
UpperSlow & 0 & 25 & 50 & 10 \\
LowerSlow & 20 & 25 & 30 & 0 \\
\hline
\end{tabular}

After all the input gained by the ultrasonic sensor, the rule base will be needed for the mobile robot to decide where the mobile robot will go, and it will be the output of the Left PWM and Right PWM. The rule base can be seen in table 3 below: 
Table 3. Rule Base

\begin{tabular}{ccccc}
\hline $\begin{array}{c}\text { Left } \\
\text { Sensor }\end{array}$ & $\begin{array}{c}\text { Middle } \\
\text { Sensor }\end{array}$ & $\begin{array}{c}\text { Right } \\
\text { Sensor }\end{array}$ & $\begin{array}{c}\text { Left } \\
\text { PWM }\end{array}$ & $\begin{array}{c}\text { Right } \\
\text { PWM }\end{array}$ \\
\hline Near & Near & Near & Slow & Fast \\
Near & Near & Far & Fast & Slow \\
Near & Far & Near & Slow & Slow \\
Near & Far & Far & Fast & Slow \\
Far & Near & Near & Slow & Fast \\
Far & Near & Far & Medium & Fast \\
Far & Far & Near & Slow & Fast \\
Far & Far & Far & Fast & Fast \\
\hline
\end{tabular}

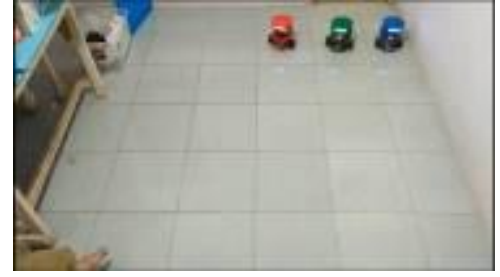

$\mathrm{t}=1$ until $10 \mathrm{sec}$

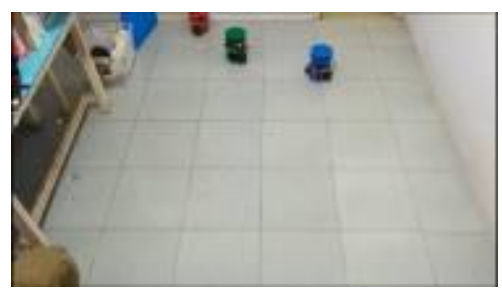

$\mathrm{t}=11-20$ second

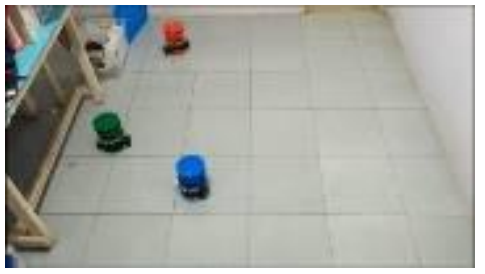

$\mathrm{t}=21-30$ second

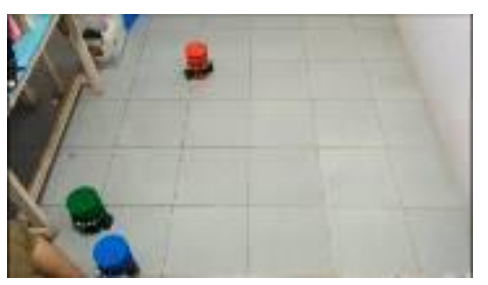

$\mathrm{t}=31-40$ second $\mathrm{t}=$ Start

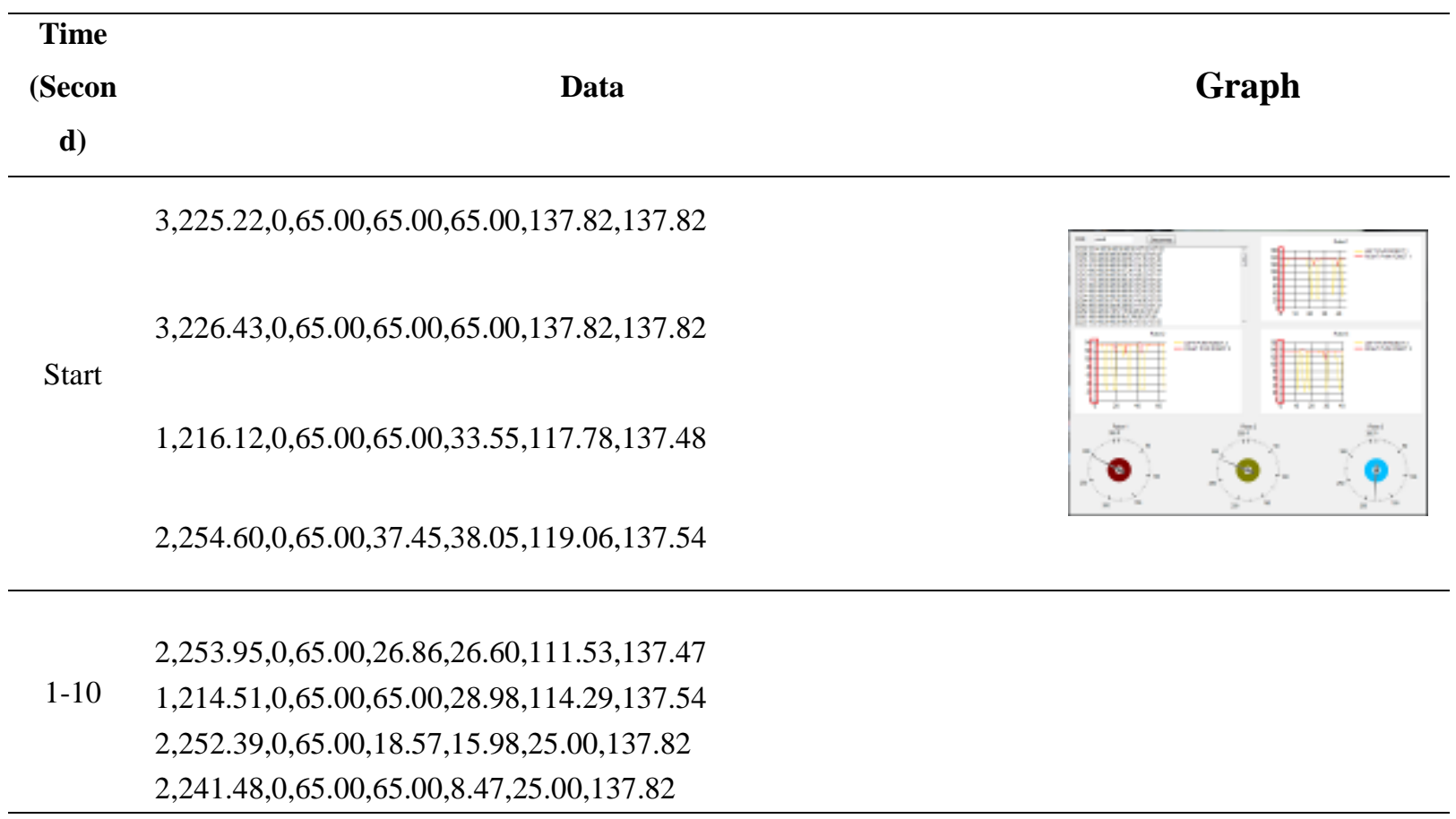


$1,213.64,0,65.00,65.00,37.34,118.72,137.54$

$2,233.36,0,65.00,65.00,65.00,137.82,137.82$

$1,213.05,0,65.00,65.00,39.78,120.52,137.47$

$2,233.44,0,65.00,65.00,65.00,137.82,137.82$

$3,228.29,0,5.00,31.24,113.81,137.68$

$2,233.00,0,65.00,47.66,65.00,137.82,137.82$

$1,213.50,0,65.00,65.00,65.00,137.82,137.82$

$3,228.68,0,65.40,56.16,137.82,137.82$

$1,213.68,0,65.00,65.00,55.05,137.82,137.82$

$1,214.08,0,65.00,65.00,65.00,137.82,137.82$

$2,232.10,0,56.48,44.84,65.00,136.23,137.82$

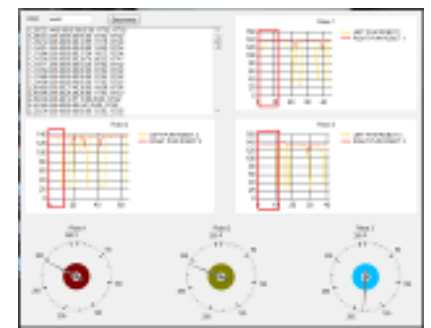

$2,230.90,0,51.34,65.00,9.10,25.00,137.82$

$1,216.36,0,65.00,65.00,58.12,137.82,137.82$

$2,235.34,0,36.88,65.00,11.53,25.00,118.40$

$2,235.53,0,41.98,65.00,12.88,25.00,129.82$

$2,227.64,0,65.00,39.66,55.72,128.89,137.47$

$2,223.89,0,59.34,60.72,54.02,137.82,137.82$

$2,223.07,0,65.00,51.66,65.00,137.82,137.82$

$2,222.55,0,65.00,65.00,65.00,137.82,137.82$

$2,221.19,0,65.00,60.05,65.00,137.82,137.82$

$2,218.74,0,65.00,65.00,22.36,105.50,137.82$

$2,214.59,0,65.00,40.14,56.72,130.67,137.82$

$2,214.02,0,65.00,53.57,49.09,137.82,137.82$

$1,195.50,15,51.69,59.97,19.91,25.00,137.82$

$2,214.68,0,65.00,33.57,31.10,113.96,137.48$

$11-20 \quad 2,216.97,0,65.00,65.00,21.43,104.12,137.82$

$2,229.43,0,65.00,65.00,8.09,25.00,137.82$

$2,333.98,0,63.43,65.00,65.00,137.82,137.82$

$2,327.70,0,65.00,65.00,65.00,137.82,137.82$

$2,319.43,0,65.00,65.00,65.00,137.82,137.82$

$2,301.00,0,65.00,65.00,65.00,137.82,137.82$

$3,331.28,15,65.00,65.00,65.00,137.82,137.82$

$2,100.84,0,65.00,57.00,65.00,137.82,137.82$

$2,64.71,0,58.00,45.41,65.00,137.82,137.82$

$3,326.83,0,65.00,60.19,58.02,137.82,137.82$

2,340.06,0,29.71,65.00,5.38,25.00,114.04

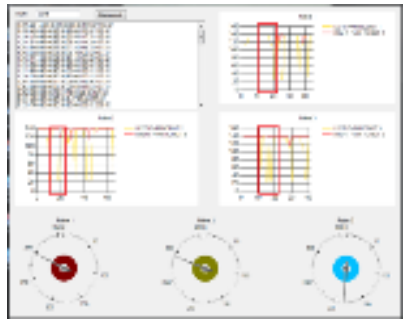

2,325.22,0,65.00,22.48,10.47,25.00,137.82

$2,325.21,0,65.00,22.00,10.84,25.00,137.82$

2,325.11,0,65.00,28.14,9.31,25.00,137.54

$2,298.13,0,65.00,62.02,21.22,104.12,137.82$

$21-30 \quad 2,294.04,0,65.00,65.00,65.00,137.82,137.82$

$2,294.63,0,65.00,65.00,65.00,137.82,137.82$

$2,294.94,0,65.00,65.00,65.00,137.82,137.82$

$1,330.72,14,65.00,65.00,65.00,137.82,137.82$

$2,295.12,0,63.71,65.00,65.00,137.82,137.82$

$2,295.10,0,56.57,65.00,65.00,137.82,137.82$

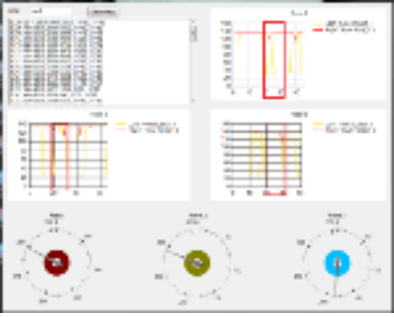


$1,331.79,11,65.00,65.00,65.00,137.82,137.82$

$3,249.52,0,65.00,48.55,31.53,113.81,137.68$

$3,247.50,0,65.00,29.59,65.00,118.05,137.60$

$1,331.79,11,65.00,65.00,65.00,137.82,137.82$

$2,294.99,0,65.00,65.00,65.00,137.82,137.82$

$3,250.64,0,65.00,65.00,65.00,137.82,137.82$

$2,295.36,0,65.00,65.00,65.00,137.82,137.82$

$2,295.39,0,65.00,65.00,65.00,137.82,137.82$

$31-40 \quad 3,209.03,0,65.00,65.00,4.17,25.00,137.82$

$3,184.71,0,65.00,65.00,65.00,137.82,137.82$

$2,295.61,0,65.00,65.00,65.00,137.82,137.82$

$2,295.08,0,65.00,62.28,53.71,137.82,137.82$

$2,293.88,0,65.00,43.02,65.00,134.87,137.82$

$2,292.95,0,65.00,65.00,65.00,137.82,137.82$

At the first time of the mobile robot run, left pwm and right pwm read for a fast movement, because there no obstacles detected by the ultrasonic sensor, so the ultrasonic sensor will read the farthest value or maximal value.

Each mobile robot read differently according to the input from the ultrasonic sensor detected from each robot. As can be seen at the 1 st second until the 10th second, each robot start to detect each obstacle and doing a move away movement from the obstacle/

At the 11th second until the 20th second, robot number 2 detected more obstacle than the other, so the graph and the data transmitted more than the other robots. The reading by the mobile robot will be transmitted and straightly received by the komputer or laptop and will be transformed into a graph using the application that already made, so the movement from the left PWM and right PWM of the mobile robot will be seen significantly..

\section{CONCLUSION}

Fuzzy logic type-2 have been applied to the mobile robot successfully. The fuzzy logic type- 2 can switch the fuzzy logic type-1 to gain a smoother movement for the mobile robot based on the enviromental situation. When the mobile robot input not detect any obstacle, it will went forward until the input detected an obstacles of, the input will be calculated to gain the output for the left PWM and the right PWM mobile robot, so it can decide where the mobile robot will go. In this situation, the left PWM and the right PWM works well. From the testing, the robots could accomplish the job well. It could avoid the obstacles which in their path.

\section{ACKNOWLEDGMENTS}

I would like to appreciate Polytechnic of Sriwijaya is fund assitance this research from early until this paper is published..

\section{REFERENCES}

[1] L. Chaimowicz and V. Kumar, "Aerial Shepherds : Coordination among UAVs and Swarms of Robots," Proc. 7th Int. Symp. Distrib. Auton. Robot. Syst., pp. 231-240, 2004.

[2] Roland, Siegwart, Illah, and R., “"Autonomous Mobile Robots,' Technology,” 2004.

[3] S. Nurmaini, S. Zaiton, and D. Norhayati, "An embedded interval type-2 neuro-fuzzy controller for mobile robot navigation," Conf. Proc. - IEEE Int. Conf. Syst. Man Cybern., no. October, pp. 43154321, 2009.

[4] Y. H. Chang, C. L. Chen, W. S. Chan, H. W. Lin, and C. W. Chang, "Fuzzy formation control and collision avoidance for multiagent systems," Math. Probl. Eng., vol. 2013, 2013.

[5] H. Hagras, “A Hierarchical Type-2 Fuzzy Logic Control Architecture for Autonomous Mobile Robots," IEEE Trans. Fuzzy Syst., vol. 12, no. 4, pp. 524-539, 2004.

[6] L. A. Zadeh, "The roles of soft computing and fuzzy logic in the conception, design and deployment of intelligent systems," Proc. 6th Int. Fuzzy Syst. Conf., vol. 1, p. 1.

[7] A. S. Handayani, T. Dewi, N. L. Husni, S. Nurmaini, and I. Yani, "Target tracking in mobile robot under uncertain environment using fuzzy logic controller," 
Int. Conf. Electr. Eng. Comput. Sci. Informatics, vol. 4, no. September, pp. 30-34, 2017.

[8] T. Jin, "Obstacle Avoidance of Mobile Robot Based on Behavior Hierarchy by Fuzzy Logic," vol. 12, no. 3, pp. 245-249, 2012.

[9] N. L. Husni, A. S. Handayani, S. Nurmaini, and I. Yani, "Cooperative searching strategy for swarm robot," ICECOS 2017 - Proceeding 2017 Int. Conf. Electr. Eng. Comput. Sci. Sustain. Cult. Herit. Towar. Smart Environ. Better Futur., pp. 92-97, 2017.
[10] K. A. Naik and C. P. Gupta, "Performance comparison of Type-1 and Type-2 fuzzy logic systems," 4th IEEE Int. Conf. Signal Process. Comput. Control. ISPCC 2017, vol. 2017-January, pp. 72-76, 2018.

[11] O. Castillo, L. Amador-Angulo, J. R. Castro, and M. Garcia-Valdez, "A comparative study of type-1 fuzzy logic systems, interval type-2 fuzzy logic systems and generalized type-2 fuzzy logic systems in control problems," Inf. Sci. (Ny)., vol. 354, pp. 257-274, 2016. 